\title{
Timing of fluoride toothpaste use and enamel-dentin demineralization
}

\begin{abstract}
Sandro Carvalho Kusano(a) Livia Maria Andaló Tenuta(a) Altair Antoninha Del Bel Cury ${ }^{(b)}$ Jaime Aparecido Cury(a)
\end{abstract}

\footnotetext{
(a) Department of Physiological Sciences, Piracicaba Dental School, University of Campinas, Piracicaba, SP, Brazil.

(b) Department of Periodontology and Prosthodontics, Piracicaba Dental School, University of Campinas, Piracicaba, SP, Brazil.
}

\begin{abstract}
It is well established that fluoride (F) prevents caries development by inhibiting demineralization and enhancing remineralization processes. However, it is not known which of these protective mechanisms is more important. In this double-blind, crossover in situ study conducted in three phases of 14 days each, 12 volunteers wore palatal appliances containing enamel and root dentin slabs, on which biofilm was allowed to accumulate under exposure to $20 \%$ sucrose solution $8 \times /$ day. F toothpaste was used once a day, either before the daily demineralizing episodes (in the morning) or after them (at night). Non-F placebo toothpaste was used in the control group. F toothpaste significantly reduced enamel and dentin demineralization compared with the control $(p<0.05)$. F toothpaste was more effective when used after the demineralization episodes than before, and this difference was statistically significant for dentin $(p<0.05)$. The results suggest that brushing with $\mathrm{F}$ dentifrice at night to remineralize daily mineral losses may be preferable to brushing in the morning to inhibit the demineralizing episodes of the day.
\end{abstract}

Descriptors: Demineralization; Dentifrice; Fluorides; Dental Enamel; Dentin.

\section{Introduction}

It is well established that the presence of fluoride $(\mathrm{F})$ ions in the oral environment interferes with dental mineral loss by inhibiting demineralization and enhancing remineralization during the dynamics of caries process. ${ }^{1,2,3}$ However, the extent to which each of these effects influences caries development is unknown, because they are difficult to isolate. Although $\mathrm{F}$ toothpaste is able to provide $\mathrm{F}$ ions to the oral cavity to interfere with both phenomena, ${ }^{4,5}$ its effect when used before or after demineralizing challenges has only been studied in vitro. ${ }^{1}$

In this in vitro study, ${ }^{1}$ no difference was observed between $\mathrm{F}$ toothpaste used to inhibit the demineralization process or to enhance the mineral repair that occurs during the subsequent remineralization. However, the effect of the timing of brushing with $\mathrm{F}$ toothpaste has not been studied under conditions that simulate clinical $F$ use, and the effect of this timing on root dentin demineralization is completely unknown.

Therefore, the aim of this study was to evaluate in situ the effects of the timing of $\mathrm{F}$ toothpaste use (i.e., before or after daily cariogenic challenges) on enamel and root dentin mineral loss, under conditions of biofilm accumulation and frequent sucrose exposure. 


\section{Methodology}

A crossover, double-blind in situ study of three phases of 14 days each was conducted after ethical requirements were met (Ethics Committee, Piracicaba Dental School, protocol 104/2009). During each phase, 12 volunteers wore a palatal appliance containing three slabs of bovine enamel and three of root dentin. ${ }^{6}$ The surface hardnesses (SH) of the dentin and enamel slabs were determined previously.

Dental biofilm was allowed to accumulate on the slabs. At eight times each day (at 8:00, 9:00, 10:00, $11: 00,14: 00,15: 30,17: 00$, and 19:00 h), the slabs were extraorally treated with a $20 \%$ sucrose solution as a cariogenic challenge. ${ }^{7}$ In the first phase, volunteers were randomly allocated to one of the following group of treatments:

- $\mathrm{G} 1$ = brushing 3 times/day (after main meals) with a placebo, non-F toothpaste;

- $\mathrm{G} 2$ = brushing 1 time/day with a $\mathrm{F}$ toothpaste $(1,100 \mu \mathrm{g} \mathrm{F} / \mathrm{g}$ as NaF, silica-based) in the morning, before the first sucrose exposure (at approximately 7:30 h), and after lunch and dinner with non-F toothpaste; or

- $\mathrm{G} 3$ = brushing 1 time/day with $\mathrm{F}$ toothpaste at night, after the last sucrose exposure (between 20:00 and 21:00 h), and after breakfast and lunch with non-F toothpaste.

The sequence of treatments used in the next two phases was also randomized and, after the three phases, all volunteers had undergone all treatments.

On the $15^{\text {th }}$ day of each phase, the slabs were removed, $\mathrm{SH}$ was determined, and the percentage of loss ( $\%$ SHL) was calculated as an indicator of demineralization. ${ }^{7,8}$ The $\mathrm{F}$ uptake by enamel and dentin was also determined.

Seven-day lead-in periods were allowed before each phase, when volunteers used the treatment assigned for the next phase. Volunteers lived in an optimally fluoridated city $(0.6-0.8 \mathrm{mg}$ F/L for the region), and drank and consumed foods prepared with this water. In general, no restriction was made with regard to the diet of the volunteers, except that they were instructed to avoid F-rich foods containing bioavailable $\mathrm{F}$, such as tea. Volunteers also received oral and written instruction to refrain from using any antibacterial substance.

\section{Enamel demineralization assessment}

Enamel and dentin slabs obtained from bovine incisors had the center of their surfaces polished flat. The baseline $\mathrm{SH}$ was determined by making three indentations, spaced $100 \mu \mathrm{m}$ from each other, with a Future-Tech FM hardness tester coupled to FM-ARS 900 software. Knoop loads of 50 and $5 \mathrm{~g}$ were used for enamel and dentin, respectively. Before dentin hardness measurements, the slabs were allowed to dry for at least $30 \mathrm{~min}$ to minimize the interference of dentin dehydration on the measurements. ${ }^{8}$

At the end of each experimental phase, $\mathrm{SH}$ was again measured in all the slabs. Three adjacent indentations were made at $100 \mu \mathrm{m}$ from the baseline measurements, and the values were averaged. The $\%$ SHL was calculated as (baseline $\mathrm{SH}-\mathrm{SH}$ after in situ test) $\times 100 /$ baseline $\mathrm{SH}$. The results of the three enamel and dentin slabs for each volunteer subjected to each treatment were averaged and analyzed statistically $(\mathrm{n}=12)$.

\section{Determination of $\mathbf{F}$ in enamel and dentin}

The surface area of each slab was measured with a digital caliper $( \pm 0.01 \mathrm{~mm})$. All other surfaces were protected with a layer of wax. Each slab was immersed in $0.5 \mathrm{M} \mathrm{HCl}\left(3.75 \mathrm{~mL} / \mathrm{cm}^{2}\right)$ for $30 \mathrm{~s}$ under constant agitation. ${ }^{9}$ The extract was buffered with an equal volume of TISAB II ( $\mathrm{pH} 5.0$ ), modified with $20 \mathrm{~g} \mathrm{NaOH} / \mathrm{L} .{ }^{9}$ The $\mathrm{F}$ concentration was determined with an ion-selective electrode (F 3005; Weiss Research, Houston, USA) and an ion analyzer (Orion EA-940; Orion Research), which was previously calibrated with standard F solutions prepared similarly to the samples. Because of the compositional difference between sound and carious enamel and dentin, the data were expressed in $\mu \mathrm{g} F / \mathrm{cm}^{2}$ rather than ppm. ${ }^{10}$ The results for each volunteer subjected to each treatment were averaged and analyzed statistically $(\mathrm{n}=12)$.

\section{Statistical analysis}

Data for enamel and dentin were analyzed independently. Analysis of variance (ANOVA) was used to determine the effect of treatment on all variables. 
To reduce unknown variability from error, volunteers were included as a source of variation (statistical blocks). Assumptions of equality of variances and normal distribution of errors were checked for all response variables tested, and variables that did not satisfy these assumptions were transformed. The SAS system was used in all analyses, and the significance level was prefixed at $5 \%$.

\section{Results}

The loss of the dentin or enamel SH was significantly less for the groups treated with $\mathrm{F}$ toothpaste compared with the control $(p<0.05$, Table 1$)$. For dentin, a significantly lower \%SHL was observed for the group using $\mathrm{F}$ toothpaste at night compared to those using $\mathrm{F}$ toothpaste in the morning $(p<0.05$, Table 1).

In enamel slabs, the $\mathrm{F}$ concentration was not significantly different between the groups using $\mathrm{F}$ toothpaste $(p>0.05)$; however, the $\mathrm{F}$ concentration was significantly higher in groups treated with $\mathrm{F}$ toothpaste at night compared to those treated with non-F toothpaste $(p<0.05)$. The difference between slabs treated with $\mathrm{F}$ toothpaste in the morning and those treated with non-F toothpaste did not reach statistical significance ( $p=0.06$, Table 1$)$. In dentin slabs, both groups treated with $\mathrm{F}$ toothpaste presented significantly higher $\mathrm{F}$ concentrations than those treated with non-F toothpaste $(p<0.05)$, with no significant difference between the $\mathrm{F}$ toothpastetreated groups $(p>0.05$, Table 1$)$.

\section{Discussion}

Based on various evidences, ${ }^{11,12}$ it is recommend- ed that adults toothbrush with $\mathrm{F}$ toothpaste at least twice a day. ${ }^{12,13}$ However, our data show that using $\mathrm{F}$ toothpaste once a day significantly reduces enamel and dentin demineralization compared with control. These findings were obtained under a high cariogenic challenge, i.e., undisturbed biofilm accumulation for 14 days and exposure to sucrose $8 \times /$ day.

Although the in situ model used may have limitations when compared to in vivo studies, our experimental data using it agree with the conclusions of systematic reviews of the literature. For instance, the relative importance of combinations of methods of topical F use, compared to F toothpaste used alone, to reduce enamel demineralization ${ }^{14}$ was studied using this model and the results were later supported by a systematic review. ${ }^{15}$ Also, our experimental data using this model to evaluate the anticaries efficacy of low-F toothpaste compared with that containing 1,100 ppm $\mathrm{F}^{16}$ are consistent with a recent systematic review showing that toothpaste should have at least 1,000 ppm F to reduce caries effectively. ${ }^{17}$ Therefore, this in situ model may be considered as a surrogate for in vivo studies to evaluate the anticaries effect of $\mathrm{F}$ dentifrice.

Considering that the actual frequency of toothbrushing is not expected to be high, especially in children, ${ }^{11,12}$ our findings support the relevance of $\mathrm{F}$ toothpaste use to explain the decrease in caries incidence reported in developed ${ }^{18}$ and developing countries. ${ }^{19}$ The higher $\mathrm{F}$ concentration in enamel and dentin slabs when $\mathrm{F}$ toothpaste was used is consistent with the F-mediated inhibition of mineral loss under cariogenic conditions, which results from the enhanced precipitation of calcium phosphates on

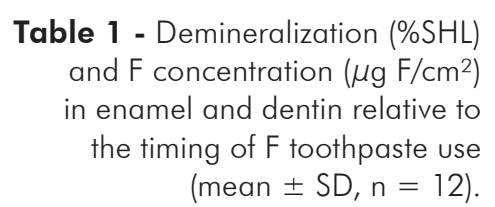

Table 1 - Demineralization (\%SHL) and $\mathrm{F}$ concentration $\left(\mu \mathrm{g} \mathrm{F} / \mathrm{cm}^{2}\right)$ in enamel and dentin relative to the timing of $\mathrm{F}$ toothpaste use (mean $\pm \mathrm{SD}, \mathrm{n}=12$ )

\begin{tabular}{c|c|c|c|c}
\hline \multirow{2}{*}{ Timing of $F$ toothpaste use } & \multicolumn{2}{|c|}{$\% \mathrm{SHL}$} & $\mathrm{F}$ in enamel/dentin ${ }^{\S}\left(\mu \mathrm{g} \mathrm{F} / \mathrm{cm}^{2}\right)$ \\
\cline { 2 - 5 } & Enamel & Dentin & Enamel & Dentin \\
\hline $\begin{array}{c}\text { None (control, } \\
\text { placebo toothpaste) }\end{array}$ & $72.0 \pm 20.8 \mathrm{a}$ & $76.5 \pm 9.3 \mathrm{a}$ & $1.3 \pm 0.6 \mathrm{a}$ & $1.8 \pm 0.9 \mathrm{a}$ \\
\hline $\begin{array}{c}\text { In the morning, before } \\
\text { daily cariogenic challenges }\end{array}$ & $41.6 \pm 21.5 \mathrm{~b}$ & $61.8 \pm 11.8 \mathrm{~b}$ & $2.0 \pm 1.1 \mathrm{ab}$ & $3.7 \pm 2.0 \mathrm{~b}$ \\
\hline $\begin{array}{c}\text { At night, after daily } \\
\text { cariogenic challenges }\end{array}$ & $30.0 \pm 15.8 \mathrm{~b}$ & $48.4 \pm 19.1 \mathrm{c}$ & $2.4 \pm 1.3 \mathrm{~b}$ & $3.8 \pm 2.2 \mathrm{~b}$ \\
\hline
\end{tabular}

$\% \mathrm{SHL}=$ Percentage of surface hardness loss. ${ }^{\S}$ Transformed to the $\log _{10}$ to fit the assumptions of analysis of variance. Groups with means followed by distinct letters differ from each other at $p<0.05$ (comparisons within columns). 
tooth mineral in the presence of $\mathrm{F}^{2,3}$

Our findings also showed that $\mathrm{F}$ toothpaste may be more effective if used every day at night (to remineralize the mineral loss induced by acids produced by biofilm sugar metabolism) than in the morning (to reduce the future demineralization to occur during the day). Lower \%SHL was observed when F toothpaste was used at night than in the morning (Table 1), but statistical significance at $5 \%$ was found only for dentin. The use of SH loss to evaluate enamel-dentin demineralization is supported by the available literature. ${ }^{8,20}$ Although our results contradict those found by ten Cate et al., ${ }^{1}$ these authors used an in vitro design, which may account for the observed differences compared to our in situ study.

Although we did not evaluate if the timing of $\mathrm{F}$ toothpaste use would result in differences in F retention in the biofilm, it is possible that use at night may reduce $\mathrm{F}$ clearance and increase its availability, ${ }^{21}$ causing lower mineral loss. This possibility should be studied in detail. Nevertheless, caries lesions are formed under cyclic events of de- and remineralization. The higher efficacy of $\mathrm{F}$ toothpaste used after daily demineralizing challenges suggests that the effect of $\mathrm{F}$ in reducing demineralization might be limited under a high cariogenic challenge, whereas its effect in enhancing remineralization might be improved under conditions favoring mineral precipitation. The high cariogenic challenge used in the present study is clinically relevant, considering the importance of $\mathrm{F}$ toothpaste use for caries control. However, the extrapolation of these results to other

\section{References}

1. ten Cate JM, Timmer K, Shariati M, Featherstone JD. Effect of timing of fluoride treatment on enamel de- and remineralization in vitro: a pH-cycling study. Caries Res. 1988;22(1):20-6.

2. ten Cate JM. In vitro studies on the effects of fluoride on deand remineralization. J Dent Res. 1990 Feb;69 Spec No:614-9.

3. Larsen MJ. Chemical events during tooth dissolution. J Dent Res. 1990 Feb;69 Spec No:575-80.

4. Cury JA, Tenuta LM. How to maintain a cariostatic fluoride concentration in the oral environment. Adv Dent Res. 2008 Jul;20(1):13-6. conditions should be done with caution.

Although the present study did not aim to compare enamel and dentin directly, the results suggest that $\mathrm{F}$ available from 1,100 ppm $\mathrm{F}$ toothpastes has a more pronounced effect on reducing mineral loss in enamel $(42 \%$ and $58 \%$ for brushing in the morning and at night, respectively) than in dentin (19\% and $37 \%$ for brushing in the morning and at night, respectively). This finding is consistent with studies showing that a higher $\mathrm{F}$ concentration or frequency of $\mathrm{F}$ application is needed to reverse dentin caries. $^{22,23}$

\section{Conclusion}

Brushing with $\mathrm{F}$ dentifrice at night to remineralize daily mineral losses appears to be more effective than brushing in the morning to inhibit the demineralizing episodes of the day. To explain these results, future research should be conducted comparing the kinetics of $\mathrm{F}$ in dental biofilm after brushing teeth in the morning or at night.

\section{Acknowledgments}

We thank the volunteers for their valuable participation and Colgate/Palmolive (São Paulo, SP, Brazil) for kindly providing the toothpaste formulations. The study was supported by a scholarship to the first author from CAPES and FAPESP (process 2009/07019-3). Preliminary reports were presented at the $89^{\text {th }}$ General Session of the IADR (San Diego, CA, USA, 2011) and the $58^{\text {th }}$ ORCA Congress (Kaunas, Lithuania, 2011).

5. Tenuta LM, Zamataro CB, Del Bel Cury AA, Tabchoury CP, Cury JA. Mechanism of fluoride dentifrice effect on enamel demineralization. Caries Res. 2009;43(4):278-85.

6. Hara AT, Queiroz CS, Paes Leme AF, Serra MC, Cury JA. Caries progression and inhibition in human and bovine root dentin in situ. Caries Res. 2003 Sep-Oct;37(5):339-44.

7. Cury JA, Rebelo MA, Del Bel Cury AA, Derbyshire MT, Tabchoury CP. Biochemical composition and cariogenicity of dental plaque formed in the presence of sucrose or glucose and fructose. Caries Res. 2000 Nov-Dec;34(6):491-7.

8. Vale GC, Tabchoury CP, Del Bel Cury AA, Tenuta LM, ten Cate JM, Cury JA. APF and dentifrice effect on root dentin 
demineralization and biofilm. J Dent Res. 2011 Jan;90(1):7781.

9. Koo RH, Cury JA. Soluble calcium/SMFP dentifrice: effect on enamel fluoride uptake and remineralization. Am J Dent. 1998 Aug;11(4):173-6.

10. Delbem AC, Carvalho LPR, Morihisa LKU, Cury JA. Effect of rinsing with water immediately after APG gel application on enamel demineralization in situ. Caries Res. 2005 MayJun;39(3):258-60.

11. Chesters RK, Huntington E, Burchell CK, Stephen KW. Effect of oral care habits on caries in adolescents. Caries Res. 1992;26(4):299-304.

12. Twetman S. Caries prevention with fluoride toothpaste in children: an update. Eur Arch Paediatr Dent. 2009 Sep;10(3):1627.

13. Davies RM, Ellwood RP, Davies GM. The rational use of fluoride toothpaste. Int J Dent Hyg. 2003 Feb;1(1):3-8.

14. Paes Leme AF, Dalcico R, Tabchoury CPM, Del Bel Cury AA, Rosalen PL, Cury JA. In situ effect of frequent sucrose exposure on enamel demineralization an on plaque composition after APF application and F dentifrice use. J Dent Res. 2004 Jan;83(1):71-5.

15. Marinho VC, Higgins JP, Sheiham A, Logan S. Combinations of topical fluoride (toothpastes, mouthrinses, gels, varnishes) versus single topical fluoride for preventing dental caries in children and adolescents. Cochrane Database Syst Rev. 2004;(1):CD002781.

16. Cury JA, Amaral RC, Tenuta LMA, Del Bel Cury AA, Tabchoury CPM. Low-fluoride toothpaste and deciduous enamel demineralization under biofilm accumulation and sucrose exposure. Eur J Oral Sci. 2010 Aug;118(4):370-5.

17. Walsh T, Worthington HV, Glenny AM, Appelbe P, Marinho VC, Shi X. Fluoride toothpastes of different concentrations for preventing dental caries in children and adolescents. Cochrane Database Syst Rev. 2010 Jan 20;(1):CD007868.

18. Bratthall D, Hansel-Petersson G, Sundberg H. Reasons for the caries decline: what do the experts believe? Eur J Oral Sci. 1996 Aug;104(4 (Pt 2)):416-22.

19. Cury JA, Tenuta LM, Ribeiro CC, Paes Leme AF. The importance of fluoride dentifrices to the current dental caries prevalence in Brazil. Braz Dent J. 2004;15(3):167-74.

20. Arends J, ten Bosch JJ. Demineralization and remineralization evaluation techniques. J Dent Res. 1992 Apr;71 Spec No:9248.

21. Zero DT, Raubertas RF, Fu J, Pedersen AM, Hayes AL, Featherstone JD. Fluoride concentrations in plaque, whole saliva, and ductal saliva after application of home-use topical fluorides. J Dent Res. 1992 Nov;71(11):1768-75.

22. Baysan A, Lynch E, Ellwood R, Davies R, Petersson L, Borsboom $P$. Reversal of primary root caries using dentifrices containing 5,000 and 1,100 ppm fluoride. Caries Res. 2001 JanFeb;35(1):41-6.

23. Laheij AM, van Strijp AJ, van Loveren C. In situ remineralisation of enamel and dentin after the use of an amine fluoride mouthrinse in addition to twice daily brushings with amine fluoride toothpaste. Caries Res. 2010 Jul;44(3):260-6. 